\title{
FEATURES OF YOUNG RABBITS INTESTINAL MICROBIOCENOSIS UNDER DIFFERENT FEEDING SYSTEMS
}

\section{Y. M. Pohilko, N. O. Kravchenko, L. V. Bozhok, V. O. Aheyev, O. M. Dmytruk}

Meat of rabbits is a dietary product containing $46 \%$ of protein, which is almost $100 \%$ digested by the human body, $11 \%$ of fats, which contain $5 \%$ of saturated fatty acids, macronutrients (calcium, iron, sulphur, sodium) and a number of vitamins (A, C, E, PP, group B). [1]. According to the Food and Agriculture Organization (FAO), world production of meat of rabbits now exceeds $2 \mathrm{mln}$. tons per year [2].

At the beginning of 2015, livestock of rabbits in Ukraine totalled 5.14 million: agricultural enterprises cultivated 129.8 thous. heads, private sector -5.012 million heads. Dynamics of livestock over the past five years was positive, that was facilitated by breeding of rabbits by small farmers and people [3].

Industrial farming of rabbits is significantly different from the private and not only by scale, but also the conditions of feeding, management, veterinary services. One of the key issues existing earlier and now is the improvement of technology of rabbit feeding. In the industrial rabbit farming, to save feed and increase the intensity of growth intensity, concentrate (dry) type of feeding with all-in-one granules was introduced [4]. In small private farms, animals are fed using combined type of feeding, which includes coarse, green and succulent feed.

The most important condition for improving productivity is the rational arrangement of adequate feeding of rabbits, especially during weaning from milking doe at day 35-45. Gastrointestinal tract of young rabbits is not sufficiently formed to digest large amounts of feed, which can lead to irregularities in its functioning, disease or even death of the rabbits. The digestion process in macroorganism depends on the activity of microflora colonizing gastrointestinal tract. Its composition is primarily driven by the type of animal feeding [4]. Under natural conditions, quantity and species composition of normal microflora of the gastrointestinal tract of rabbits is supplemented by coprophagia. Under conditions of industrial rabbit farming, natural process of formation caecotrophs is broken because there is no communication with soil, green mass of plants, which necessitates the use of probiotics. Increase in the number of beneficial bacteria stabilizes the intestinal microflora balance, and thus increases gain of live weight of animals by $10-15 \%$, expenditure of feed per unit of production is reduced by $5-10 \%$, and also the incidence of gastrointestinal diseases rabbits decreases [5].

A small amount of data in the literature on the influence of type of feeding and its components on the intestinal microbiocenosis of young rabbits induced us to conduct a study on this issue.

Materials and methods. Study was conducted in the laboratory of the Institute of Agricultural Microbiology and Agroindustrial Manufacture of NAAS on laboratory animals (scrub rabbits).

To study the composition of intestinal microbiocenosis in young rabbits in different feeding systems, experiment 1 was initiated: animals were divided into two groups of 5 rabbits in each starting from day 24 to 94 of life. Rabbits of the $1^{\text {st }}$ experimental group were fed by the concentrate type of feeding: compound feed Agrovetkorm (Ukraine), which was $100 \%$ of the diet; group 2 - by the combined type of feeding (by P. Kurliak) [6]: grain constituted 11\%, succulent feed $-12 \%$, green mass $-70 \%$ coarse feed $-7 \%$.

To investigate the influence of components of the combined type of feeding on the composition of gastrointestinal microflora of young rabbits, experiment 2 was conducted: animals were divided into three groups of 5 rabbits in each starting from day 24 to 94 of life. Rabbits of the $1^{\text {st }}$ experimental group were fed mainly with herbage of meadow grass $(90 \%)$, grain, hay, root plants made up the rest of feed; $2^{\text {nd }}$ group was fed with hay of meadow grass $(90 \%)$, and the rest - green mass, grain and root plants; $3^{\text {rd }}-$ wheat and oats $(90 \%)$, the rest green mass, hay, root plants.

For microbiological studies, litter was sampled every 5 days beginning from the day 21 . The species and quantitative composition of microbiocenosis in the gastrointestinal tract of 
young rabbits was measured by inoculation of samples from intestine on selective culture media: bifidobacteria - on Blaurock medium, lactic acid bacteria - on cabbage agar (by Ye. I. Kvasnikov) and MRS (by J. C de Man, M. Rogosa and M. E. Sharp); a group of intestinal bacteria - on Levin medium; E. coli - on blood agar (MPA with 10\% rabbit blood), enzymatic activity (ability to ferment lactose) was investigated by cultivation on Hiss medium with the addition of $1 \%$ carbohydrate, yeast-like fungi - on Sabouraud medium with $0.1 \mathrm{~g} / \mathrm{L}$ of antibiotic ciprofloxacin, anaerobic bacilli - on MPA medium [7]. The identification of grown microorganisms was performed by morphological, cultural, physiological, and biochemical properties [8].

The total number of bacteria was calculated by the equation:

$$
\mathrm{X}=\mathrm{Z} \cdot 10^{\mathrm{n}} / \mathrm{Y},
$$

where $\mathrm{X}$ - number of bacteria, $\mathrm{CFU} / \mathrm{g}$; $\mathrm{Z}$ - number of colonies grown; $10^{\mathrm{n}}$ - value reciprocal to diluation;

$\mathrm{Y}$ - cultivated dose, $\mathrm{mL}$.

Statistical processing of the obtained results was performed using Microsoft Excel.

Therefore, dependence of quantitative and species composition of microbiocenosis of young rabbits from the type of feeding was established during the study. It was found that in the concentrate type of feeding, number of bifidobacteria and yeast-like fungi has been increased.

The influence of the components of the combined type of feeding on the composition of the microflora in the gastrointestinal tract of young rabbits was studied. It was determined that the introduction of significant proportion of hay in the diet of rabbits leads to the reduction of the number of bifidobacteria and increase in the number of anaerobic bacilli, and the diet, based on grain showed increase in the number of lactic acid bacteria and reduction in the number of yeast-like fungi. 